\title{
ERP Adoption by Moroccan ICT companies: Human Factor vs. technological change
}

\author{
Hajar Slimani $^{1 *}$, AnissMoumen ${ }^{2}$ \\ ${ }^{1}$ LEREMCE,ENCG Meknes, Moulay Ismail University, Morocco \\ ${ }^{2}$ Laboratory of Engineering Sciences, ENSA Kenitra, Ibn Tofail University, Morocco
}

\begin{abstract}
Nowadays, a new vision of change management becomes a real challenge when companies introduce an ERP Project. This article aims to discuss the changes and the otherorganizational evolutions that can impact the company and establish an inventory of the different variables that underlie performance and promote or block the success of ERP project into ICT in companies.
\end{abstract}

\section{Introduction}

A successful company is one that not only changes but changes rapidly and continuously increases its culture of change. This notion is inseparable from performance, it represents both the expected result and the resource and management method put in place. It is also essential to know that this choice of management and work method can even become a competitive advantage, but only if the process is well managed and directed, hence the importance of implementing a change management approach.

However, the theoretical analysis of organizational effectiveness concerns the person and the managers while placing them as actors in the strategic arena of each company. The links between strategy, technology and change situate the individual within the otherdimensions and methodsto change. Since the human factor emerges from the historical approach, we believe that it is necessary to go even deeper into the concepts that position him as the main actor in the organization.

The literature review that we have carried out in this sense confirms our choice on the importance of this factor. Indeed, in the centre of this field, we found that the management of the human factor becomes a fundamental element, the most advanced technologies cannot fulfil their promises if this last one refuses to adhere to it.

This article focuses on analyzing the relationship between ERP technology, change management and the performance obtained or expected following its implementation, and the human factor's management. Studying this issue is a highly topical subject that responds to researchers' concerns and practitioners. In this study, we try to provide the necessary

*Corresponding author:h.slimani@umi.ac.ma 
answers concerning the link between technological change, human factors, and performance? Moreover, how can we objectively measure this contribution? We, therefore, wish to clarify the notion of the subjectivity of the different perceptions that this qualification of performance entails in a technological change of the ERP type.

\subsection{The part of the human factor in a new method of change}

\subsection{Methods of change}

To better analyze the part of the individual in a change process, we based on Demers (1999) theory with its three main periods while emphasizing the part of the human factor in the organization's evolution.

In the first period, the author defines the change in growth, development, and adaptation. According to contingency theory (the 1970s), the durability and performance of organizations depend on adaptingtheir environment. The leader here played the part of an orchestra conductor while ensuring the coherence between several elements determining the organization, such as its strategy, structures, and systems, with the otheraspects, specific to each environment. The end of this period was marked by other theories that give human capital a privileged place, which provides them witha precursory character. The new idea is that adaptation can therefore not be the result of a rational approach planned by leaders, but can also come from an organizational process, the outcome of which may escape the leaders in part. The principle of these theories is always situated within the framework of a gradual and predictable adaptation of the organization, which was strongly questioned by the second period.

Indeed, the second period dramatic events marked the change processes, affecting several spheres of the company. The signicant strength of resistance characterized These changes, which provoked discontinuity and insecurity for the people. Leaders have a crucial mission : to give meaning to the new construction of which they are the builders. The objective here is the gradual improvement of work efficiency and organizational quality of life, thus coming closer to the concerns of the individual as an actor of change. But the general perspective of this period remains puts the leader at the top, seeing the change from above.

Therefore, to achieve our objective of historical analysis of change, we give the name of "the modern period" for this third period, and we will not dwell on all the currents that have marked this period. However, instead we will cite some traits that seem to recur in current analyses, such as the instability of the environment, the acceleration of economic cycles, the permanent change of competitive rules, without forgetting the technological innovation that changes the world. Change here is no longer a dramatic event but becomes a recurring phenomenon. Thus, to cope with these unpredictable events, organizations are forced to give each member of the organization more freedom and initiative. That makes change everyone's business instead of being the product of rational planning.

Many authors have approached change from this perspective, such as evolutionary theories and constructivist methods that define organizations as systems that adapt by learning through stable processes that produce change continuously. But what is interesting in this modern period is that we do not privilege one type of change (incremental or radical, planned or emergent...). However, we focus on the part of individuals as participants in an 
organizational dynamic according to her position, on belonging, hierarchical status, access to power and resources. Managers become actors, among others.

So we can say that the modern vision describes the change as an element that is part of the daily reality of organizations. And this dynamic of organizational change is specific to each company, which may come from its culture, history, and individuals who compose it.

Consequently, the modern vision is more interested in the organization's capacity to change and adapt than in the preoccupation with change direction. This vision seems to be much more complete and corresponds better to the reality of the field.

\subsection{New vision of technological change}

Theoretically, the mere adoption of new technologies does not guarantee their potential benefits. But the extent of its impact varies considerably between companies, sectors and countries and can be hindered or helped by several complementary factors. This issue gives rise to three postures:

- Technical acceptance: this means talking about IT with the notion of technical contingency. The organizational choice is considered a spontaneous choice that represents the image of external constraints.

- Organizational tyranny: this is the opposite perspective of the first posture.

- The organizational structure is a thoughtful action where the technique is a deliberate choice that follows the appropriate means.

- And that of emergent thinking: which brings together the interaction between the two perspectives (technical and organizational) with a third axis which is the social context that has a substantial impact on technical change, known in theory as "socio-technical".

Two visions currently held on technical change: technicality, whose materialist analysis is based on a relativelydeterministic logic, and that of the sociology of organizations, which offers a more interaction perspective.

\section{Analysis of people's attitudes towards change}

\subsection{Attitudes towards technological change}

Most of the time, the announcement of the change will constitute a general disruption It will follow a specific process where each stakeholder is confronted with several,significant challenges, which will impact what he already knows and on what he is currently doing. In this perspective, resistance to change is entirely legitimate. They have deep-rooted reasons and not just simple psychological reactions of lousy temper.

In theory, we have observe that the behaviour of individuals in the face of change can be interpreted at various levels these behaviours are no always in opposition to the change, i.e. individuals do no always react negatively to it. For the technological change, oppositioncan be qualified as voluntary because the actor knows the reasons for his refusal to change or involuntary when the oppositionis related to his lack of skills and knowledge of the tools. In this regard, Dufour and Ouimet (1997) identify five leading causes of resistance on the part of actors that can be observed in most technological change situations:

- Individuals resist change when they have to give up their habits. 
-Fear of the unknown pushes individuals to resist change.

- Individuals resist change when they lack the self-esteem to face technical obstacles.

- People resist change when their economic security is at stake.

- People resist change when they are victims of their perceptions.

Therefore, the change process must include the necessary strategies and methods to facilitate the transition from the current situation to the desired situation.

Traditionally, change managers have based their ICT acquisition and implementation on technical aspects, focusing on processes, systems and technologies to deploy their vision and strategy. Although these aspects are essential, it has been demonstrated that the chances of success are considerably reduced if we do not considerthe adaptation process of individuals to change. We realize that the organization is made up of a set of components, among which the game of the actors occupies a decisive place. Although there is no recipe or miracle methodology to facilitate the acceptance and adhesion of actors to change, we are aware that a successful approach requires a remarkable ability to understand human attitudes and behaviours in the process of integrating the human aspect to technological change.

\subsection{Theoretical models of technological acceptance}

The first model that interests us in this research is the TOE (Technology - Organization Environment), founded and developed by Tornatzky and Fleischer (1990); it is used to study the determinants of adoptingof new technology. It is used to explore the factors that can influence an organizational or social phenomenon during the implementation of a complex technological innovation, such as adopting an ERP system. In his work, the author of this model states three contexts that can influence the processes by which companies adopt technological innovations. These are: "technological, environmental and organizational context".

These three elements are often used to explain adoption and assimilation, the critical factors of success or failure in complex technological investment.

The theoretical framework (TOE) has been tested and validated by researchers, for example, the work conducted by Ramdani and Kawalek (2009), which analyzed and classified the otherfactors impacting the decision-making process of new technologies adoption (ERP, CRM, SCM...). The result of their study shows that adoptingERP by companies is influenced by two main contexts of the framework (TOE): the technological context and the organizational context, and that the environmental/social context does not have a significant impact.

The (TRA) is based on the individual's judgment and behavioural intention, and was developed in various studies and attracte many researchers interesting by studying the part of the individuals behaviour to explain the resistance factors.

In our study, this theory has aroused our interest because it has been particularly successful in the field of acceptability of computer tools, in particular, the adoption and insertion of information and communication technologies in an organizational context.

According to the related theories, Davis (1986) developed a new technology acceptance model called (TAM), which admits that the intention determines the behaviour, and the attitude towards the new technology, which is influenced by two concepts "the perceived 
utility and facility". This model investigates the mediating part between these two specific beliefs and presents them as variables of crucial importance for the acceptance behaviour of new technology. The author defined perceived usefulness as "the assessment of the user's subjective likelihood that the use of computer technology or system will increase theirperformance in performing tasks. In contrast, easy to use represents a variable that describes the degree to which the user expects the respective application to be easy to use. However, several theories synthesize the variables in the form of basic constructs or even lists. In this sense, we have observed that the factors identified in these theories are mainly sociocognitive as they are the perception of usefulness and facility to use, subjective evaluation and social influence. Furthermore, the work presented indicates that the acceptance and adoption of the technology cans be considered through attitudes and behavioural intentions.

\section{ICT implementation and use factors: the ERP case}

\subsection{ERP and change management}

To clarify the link between ERP and the change management approach, we would like to briefly recall a few concentric works: Lewin (1947) and his three stages (decrystallization, transition, recrystallization), which offer a chronological, linear vision of the change process, neglecting the interaction between the actors of change. His model is only concerned with overcoming staff inertia and resistance to change. The dynamic aspect seems not very well developed in his approach. Collerette et al. (1997) propose a constructivist-systemic approach where she defines other necessary steps to understand the change process, based on four phases. The awakening: which raises the question about the usefulness of the tool.

- Disintegration: adverse reaction and attitude towards the change.

- Reconstruction: positive reaction and attitude to the change.

- Integration: the ability of the company to mix the new situation with the old practices and designs still in use.

All this lead the company to set up a set of activities in the ERP project: (communication, training, motivation, membership, the project team's composition.....). Moreover. Maaloul and Mezghani (2003) integrate involvement, communication and training within the "change engineering" dimension, which acts as a support for adapting organizational processes to the ERP.

In summary, we can group the theoretical currents mentioned into two leading currents of thought:

- The first speaks of resistance to change as a legitimate reaction.

- The other states that human beings are natively open to change, but it is how change is approached that induces resistance.

We are followers of the second trend and consider, in our case, that ERP as new technology is insteadneutral; its impact depends on the way it is implemented and used in a given environment. This idea of neutrality has allowed us to compile a list of literature on resistance to change and the associated factors. 


\subsection{ERP and human factors}

The literature review on ERP implementation highlighted the lack of specific studies on human factors in an environment of implementation of new technologies and the key success factors for its adoption. Indeed, the introduction of ERP is in itself a major change with specific aspects, and few authors have sought to understand the reasons behind the failure or success of this type of software package so eagerly awaited with companies and to analyzing its link with organizational change as we wish to do.

In perspective closer to our research field, Markus et al. (2000) have stated in their work a set of technical elements to be taken into consideration when implementing an ERP, starting with :

- The integration of business processes throughout the organization.

- Optimization and maximum use of the modules and functionalities provided witha supplier.

- Process reengineering and the use of best business practices

- The need to work with user-friendly interfaces to specific systems.

- The constant evolution of infrastructures, functionalities, versions and procedures.

So the author has highlighted the elements which link the technical tool aspects, to its users, namely :

- The staff has to adapt to the tool in question.

- They must work in homogeneous groups.

- Individuals may be led to work in collaboration with other teams within or outside the organization.

- The ERP, with its technical management capacity, can highlight errors in the processing of information withusers, which can create conflicts and generate resistance.

- The implementation or evolution of the ERP will generate a permanent change process, whether upstream or downstream or during the learning phase.

This situation reminds us of the magnitude of the changes that employees undergo during implementing an ERP. It is not surprising to note the importance that practitioners place on this in their post-implementation observations regarding the approach to this type of management software. Thisbehaviourtheoretical reflection leads us to look for the factors that empirically explain the success or failure of a successful implementation.

\subsection{ERP and technology investment performance}

To broaden this study, we have found that research in information systems management is closest to our approach. And that some elements of these otherresearches will help us to complete the puzzle of our theoretical model.

Indeed, researchers have focused on the IS success and faced the lack of objective measures. They have begun by considering users' perceptions as a measure of success, based on the users' satisfaction, several researchers find a new validated measure of this satisfaction. We retain for this research the model developed by DeLone W. and McLean E. (1992) where they demonstrated that the IS success can be evaluated by the following elements: the quality of the computer system, the quality of the information, the effective use and the satisfaction of the users. This model is based on ainstead cognitive vision of the 
information system; its measurement determinant is the users' satisfaction and the individual impacts that will allow the success of a technology. But, it is essential to specify that there was no complete practical test that verifies all these relationships. So, to fill this gap, Seddon\&Kiew $(1994,1996)$ made some modifications to the Delone\& Mclean model, where they added a new dimension, namely "user involvement".

The authors of this model insisted on the variable user satisfaction as the most crucial measurement scale in IS success.

However, it is essential to specify that this model has given more importance to the technical dimension and little to the organizational dimension generated with the adoption and implementation of the latter.

Therefore, we would like to complete the previous models with another one which also deals with the implementation of ERP, but which takes into account several factors such as (technology, organization, strategy and the human element) it is that of Imen MAALOUL (2003), or she presented four primaryfactors of success: (quality of the system, quality of information, usefulness and engineering of change)

The author states in this work that "if a company wants to incorporate an ERP system, even though its operations are not integrated, it should not only buy a software package and associated computer equipment, but it is also called upon to acquire know-how and set up an appropriate work organization. We agree with this statement and position ourselves in parallel with this work and consequently, the results of this work bring us two crucial elements for our study.

- The first element is the enumeration of the primarytechnical factors.

- The second element is the approach led with the company and the strategy adopted in front of this transformation.

\section{Research methodology}

In our research we choose an adapted positioning with a hypothetical-deductive logic. The first objective is to contextualize the model derived from the literature with exploratory study. The second aims to test this model from the perspective of confirmation or invalidation. This choice implies the use of a mixed methodological approach, successively combining qualitative and quantitative methods.

The most suitable data collection method for our study is the questionnaire survey because it allows the collection of data from a large population, it also ensures the reliability of the results obtained, thanks to the uniformity of the answers, especially in the case of closed questions. We opted for the non-probability sampling method, specifically that of convenience sampling, given the absence of a database containing the list of companies using ERP systems. We also conducted a pre-test with experts in information systems and with a sample of 30 people to ensure the understanding of the questionnaire and the validity of our measurement instrument. 


\section{Results and discussion}

Our first empirical analysis developed descriptive questions to ensure the adequacy of the results obtained from the statistical analysis. In this sense, we have created a question allowing the respondent to prioritize the most relevant factor for the success of the ERP project (Table $\left.\mathrm{N}^{\circ} 1\right)$

Table 1: Ranking of the most relevant factors for the success of the ERP project according to the

\begin{tabular}{|c|c|c|c|}
\hline Priority order & $\begin{array}{c}\text { High } \\
\text { priority }\end{array}$ & $\begin{array}{c}\text { Medium } \\
\text { priority }\end{array}$ & $\begin{array}{c}\text { Not } \\
\text { priority }\end{array}$ \\
\hline Facteur Humain & 94 & 54 & 58 \\
\hline $\begin{array}{c}\text { Facteur } \\
\text { Organisationnel }\end{array}$ & 38 & 81 & 48 \\
\hline $\begin{array}{c}\text { Facteur } \\
\text { Technique }\end{array}$ & 68 & 65 & 94 \\
\hline TOTAL OBS. & 200 & 200 & 200 \\
\hline
\end{tabular}

This question allowed us to understand that the most essentialfactor according to Moroccan companies for the success of an ERP project is "the human factor and the organizational factor". This result is in line with our statistical analysis where we showed a causal link between the "organizational dimension and technological performance" and that "the "human factor moderates user satisfaction" with the ERP tool".

Then, we elaborated in our questionnaire a grid of items containing several factors directly linked with our three main dimensions, "technical, organizational and human" to carry out a confrontation between our theoretical construction with the empirical reality. The objective isto compare our theoretical construct with the empirical reality, and to highlight the factors that the respondents considered to be the most explanatory empirically for each of the dimensions. Figure $\mathrm{N}^{\circ} 1$ presents the factorial analysis carried out on the organizational dimension.

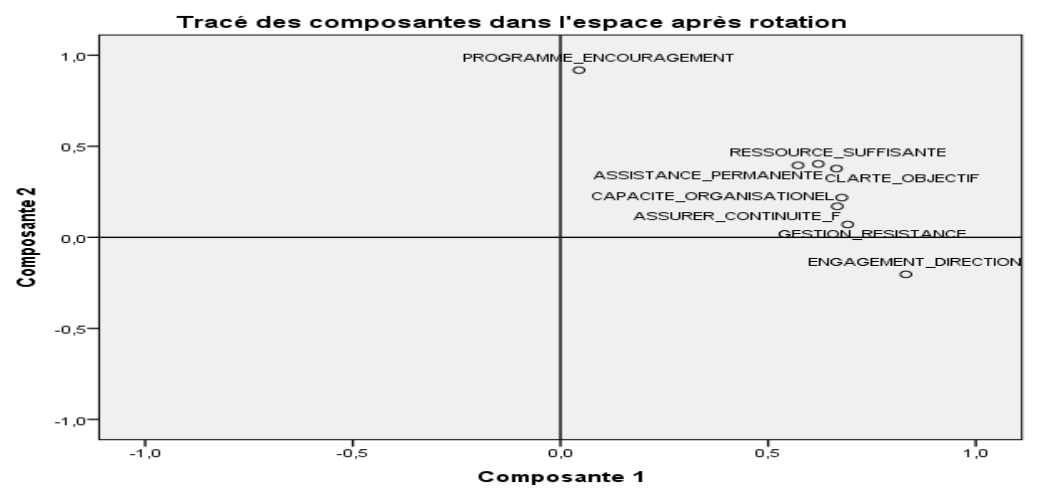

Fig. 1.Factorial map regrouping the most significant items regarding the organizational dimension 
As we can see, the figure highlights the distribution of respondents according to the most relevant organizational factors. We notice in this figure that the items are scattered with a higher density in the first class while the second class contains only one item. This observation allows us to conclude that two organizational axes must be taken into consideration for the success of the ERP project.

- A secondary axis: This concernsthe creation of an employee incentive and reward program.

- And a primary axis: Which groups all the strategic axes that the company must put in place to accompany the project in terms of "allocation of sufficient resources, the commitment of management, implementation of a training program, clarity of objectives". We conclude that the communication and change management strategy in companies will be even better with the implementation of an incentive and reward program.

Following the same approach, we will analyzingthe data obtained in the field concerning the most relevant human factor from the graph presented in the figure below (figure $\mathrm{N}^{\circ} 2$ ).

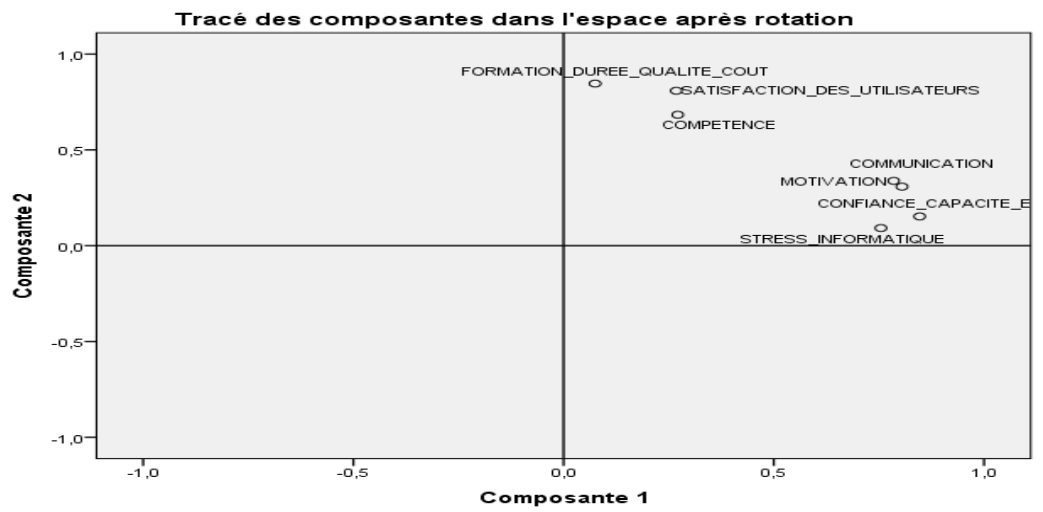

Fig.2. Factor map regrouping the most significant items of the human factor

We notice in this figure that the items are scattered in all the classes with a greater density in the first and second axis. This observation allows us to state that there are 2 axes that condition the success of an ERP project from a human factor point of view.

- A secondary axis: containing training, user satisfaction and skills.

- And a primary axis: Containing communication, stress towards the use of a new IT tool, developing confidence in the company's ability to manage a new technology.

The conclusion we can draw from this finding is that the respondents agree that their companies have taken the necessary measures to manage human factors with ensuring that they have qualified and competent personnel, ensuring user satisfaction and providing them with quality training programs.

There was a substantialconsensus among respondents about the importance of human factors management. Indeed, other factors such as "effective communication, fear of using new technology and confidence in the company's ability to manage this technological change are also perceived as fundamental for the success of the ERP project.

Following the same approach, we will analyzingthe most relevant data to be taken into consideration to better frame the technical extent and ensure the success of the ERP project. The figure below presents the graph concerning these items. 


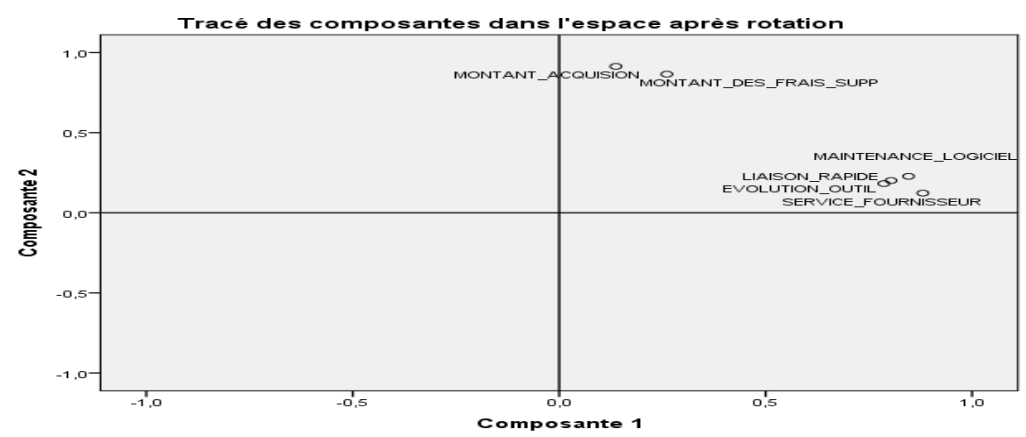

Fig. 3.Factor map regrouping the most significant items regarding the technical dimension

According to the figure above, we remark that there are two axes that condition the technical success of an ERP project:

The first one: groups items with a technical and ergonomic character of tools, such as: "software maintenance, rapid connection with the various modules, service offered with the software provider, tool development and theirability to follow the evolution of the company".

The secondary axis: Is focused on the financing aspect, such as: "the amount of investment devoted to the purchase of the software package and the number of additional costs to support updates".

This results could perhaps be divided into three aspects (financial, technical and IT support, user-friendliness and ergonomics of the tool).

\section{CONCLUSION}

Finally, it is essentialto note the principal place that ERP systems are currently taking in Moroccan companies through this study. These integrated management systems, which constitute more and more the backbone and the keystone that consolidates the strategy and the company's competitiveness, require a particular attention, in particular, in their installation and implementation. Today, ERP systems are no longer a simple technological investment, Stilla technological know-how to be provided to the staff, thanks to which the company can distinguish itself and face the changing environment.

Our research results are close to the works in "Management of information systems" relating to the determinants of IS success. We have concluded that the organizational dimension mentioned in previous studies remains a significant determinant of the success of this technological tool in the Moroccan company and that the current trend, relating to the implementation of ERP systems, demonstrates the partthat the human factor can play in its success. Technological performance depends more and more on an organizational as well as a human dimension. 


\section{References :}

1. Burnes, Bernard (2004). "Kurt Lewin and complexity theories: back to the future? » Journal of change management 4, no 4: 309-325.

2. Collerette, Pierre, Gilles Delisle, et Richard Perron (1997). Le changement organisationnel: théorie et pratique. PUQ.

3. David Autissier, Jean-Michel Moutot (2003). Pratiques de la conduite du changement :Comment passer du discours à l'action. dunod.

4. Davis, Fred D (1986). « A technology acceptance model for empirically testing new end-user information systems ». Cambridge, $M A$.

5. DeLone, William H., et Ephraim R. McLean (1992). « Information systems success: The quest for the dependent variable ». Information systems research 3, no 1: 60-95.

6. Demers, Christiane (1999). « De la gestion du changement à la capacité de changer. L'évolution de la recherche sur le changement organisationnel de 1945 à aujourd'hui ». GESTION-MONTREAL- 24: 131-139.

7. Deng, Xiaodong, William J. Doll, Anthony R. Hendrickson, et Joseph A. Scazzero (2005). " A multi-group analysis of structural invariance: an illustration using the technology acceptance model ». Information \& Management 42, no 5: 745-759.

8. Fishbein, Martin, etIcekAjzen (1977). « Belief, attitude, intention, and behavior: An introduction to theory and research ».

9. Kiew, Min-Yen, et Peter Seddon (1994). " A partial test and development of the DeLone and McLean model of IS success ». ICIS 1994 Proceedings 4, no 1: 99-110.

10. Koenig, Gérard (2012). "Le concept d'écosystème d'affaires revisité ». Management 15, no 2: 209-224.

11. Lim, Sanghee, Terence JV Saldanha, Suresh Malladi, et Nigel P. Melville (2013). « Theories used in information systems research: Insights from complex network analysis ». JITTA: Journal of Information Technology Theory and Application 14, no 25.

12. Maaloul, Imen, et LassaâdMezghani (2003). «L'implantation des ERP et ingénierie du changement: Les déterminants de la satisfaction des utilisateurs d'un ERP dans les entreprises tunisiennes ». In XIIèmeConférence de l'AssociationInternationale de Management Stratégique.

13. Markus, M. Lynne, et Cornelis Tanis (2000). « The enterprise systems experience-from adoption to success ». Framing the domains of IT research: Glimpsing the future through the past 173, no 2000: 207-173.

14. Ramdani, Boumediene, Peter Kawalek, et Oswaldo Lorenzo (2009). "Predicting SMEs' adoption of enterprise systems ». Journal of Enterprise Information Management 22, no 1/2: 10-24.

15. Tornatzky, Louis G., Mitchell Fleischer, et A. K. Chakrabarti (2013). « The processes of technological innovation. Issues in organization and management series ». Lexington Books 10 . 